\title{
NARRATIVAS SOBRE A PANDEMIA POR COVID 19 NOS ESTADOS DO AMAZONAS E RORAIMA
}

\author{
PANDEMIC NARRATIVES BY COVID 19 IN THE STATES OF AMAZONAS AND \\ RORAIMA
}

\author{
Heloísa Helena Corrêa da Silva ${ }^{1}$ \\ Maria das Graças Santos Dias ${ }^{2}$
}

\section{RESUMO:}

Trata-se de estudo exploratório descritivo transversal que objetiva apresentar aspectos da pandemia por Covid 19, que desencadeou a maior crise sanitária do século XXI, a partir das diversas narrativas sobre o tema e dados nos estados fronteiriços de Amazonas e Roraima numa linha do tempo que abarca o primeiro caso acontecido em março de 2020, em Manaus capital do estado do Amazonas e na capital de Roraima Boa Vista, em abril de 2020, evidenciando os impactos sociais e econômicos até o mês de maio do corrente ano, com uma "mirada" nos países com os quais esses estados estabelecem fronteiras. O estado do Amazonas, no Alto rio Negro estabelece fronteiras com Colômbia e Venezuela e no Alto Solimões com Colômbia e Peru e o estado de Roraima ao norte com a Venezuela e a noroeste com a República da Guiana. Os dados foram coletados em três momentos diferentes, sendo por meio do acesso ao Sistema de Notificações da Covid 19 das secretarias dos estados, disponibilizados nas mídias e do Ministério da Saúde e através dos relatórios das comissões de combate à Covid 19 nas fronteiras, e ainda, a observação sistemática das mídias locais. Concomitante às observações e verificações dos dados procedeu-se com a pesquisa bibliográfica. $\mathrm{O}$ conjunto dessas ações evidenciou que o tema no atual estágio ainda é incipiente de problematizações das narrativas desde o surgimento da pandemia pelo Covid 19, que provocam ilações desde uma possível terceira guerra, o que para fins deste artigo não se abarcou, até a narrativa da pandemia por Covid 19 como um fato social total, conceito sobre o buscou-se erguer este artigo. A crise sanitária e os impactos econômicos e sociais demonstram dados preocupantes das condições de vida e saúde, que foram negligenciados nas agendas públicas do país e nos estados, espaços das narrativas, em pauta.

Palavras chave: Pandemia, Covid 19, Crise Sanitária.

\section{ABSTRACT}

his is a cross-sectional exploratory study that aims to present aspects of the pandemic by Covid 19 , which triggered the biggest health crisis of the 21 st century, based on the various narratives

1. Professora doutora da Universidade Federal do Amazonas - UFAM. Departamento de Serviço Social e do Programa de Pós Graduação Sociedade e Cultura na Amazônia - PPGSCA. № ORCID 0000-0002-0777-5808

2. Professora doutora da Universidade Federal de Roraima - UFRR. Departamento de História e do Programa de Pós Graduação Sociedade e Fronteira - PPSOF. № ORCID

Agradecemos ao Grupo de Pesquisa Questão Social e Serviço Social no estado do Amazonas - GPQSSS e ao Grupo do Encontro de Políticas Publicas para a Pan-Amazônia e Caribe-EPPPAC, pela atualização diária dos dados do Alto Solimões e de São Gabriel da Cachoeira. 
on the subject and data in the border states of Amazonas and Roraima in a timeline that covers the first case that took place in March 2020, in Manaus, capital of the state of Amazonas and in the capital of Roraima Boa Vista, in April 2020, showing the social and economic impacts until the month of May this year, with a "look" in the countries with which these states establish borders. The state of Amazonas, in the Upper Rio Negro establishes borders with Colombia and Venezuela and in the Upper Solimões with Colombia and Peru, and the state of Roraima to the north with Venezuela and to the northwest with the Republic of Guyana. The data were collected at three different times, through access to the Covid 19 Notification System from the state secretariats, available in the media and the Ministry of Health and through the reports of the commissions to combat Covid 19 at the borders, and also, the systematic observation of local media. Concomitant with the observations and verifications of the data, we proceeded with the bibliographic search. The set of these actions showed that the theme at the current stage is still incipient of problematizations of the narratives since the pandemic emerged by Covid 19, which provoke conclusions since a possible third war, which for the purposes of this article did not cover, until the narrative of the pandemic by Covid 19 as a total social fact, a concept about which we sought to raise this article. The health crisis and the economic and social impacts show worrying data on living and health conditions, which were neglected on the country's public agendas and in the states, spaces of narratives, on the agenda.

Keywords: Pandemic, Covid 19, Health Crisis.

\section{INTRODUÇÃO:}

Convém destacar nesta introdução que a $\mathrm{OMS}^{2}$ definiu que a doença respiratória provocada pela infecção do novo Corona vírus fosse chamada de Covid19. O nome da doença resulta das palavras " corona", " vírus" e " doença" com indicação do ano em que surgiu (2019) (MORALES, 2020).

Mediante discussão ocorrida no dia 11 de março de 2020, segundo noticiado pela OMS por meio de declaração, apontou que a doença provocada pelo novo coronavirus Covid19 como uma Pandemia. Tal decisão foi pronunciada pelo chefe da agencia, Tedros Ghebreyesus, na cidade de Genebra. Segundo a página oficial da FIOCRUZ, essa doença surgiu no final de dezembro, na China e está presente agora em 117 países. O chefe da OMS apontou que, nas últimas duas semanas que antecederam a declaração realizada, o número de casos novos que surgiam diariamente na China aumentou na proporção de 13 vezes. Os números não foram apenas isolados na China, os países que já substancialmente contraíram a doença havia triplicado.

Vale ressaltar que, até a data da declaração haviam sido registrados mais 118 mil casos e 4.291 mortes no mundo. Ghebreyesus afirmou que "milhares de pessoas estão lutando pela vida em hospitais" e que "nos próximos dias e semanas, o número de casos, de mortes e de países afetados subirá ainda mais".

A crise sanitária mundial tem como catalizadores pessoas da classe média e viajaram para o exterior. Seguindo protocolo da OMS o Brasil teve seu primeiro caso registrado na cidade de São Paulo, que mantém o maior número de casos de Covid 19 no país. A crise sanitária no Brasil provocada pela pandemia por Covid19, que tem se mostrado como a maior da América Latina, aflorou a crise estrutural e incidiu sobre os serviços públicos de atenção à saúde,

\footnotetext{
${ }^{2}$ Organização Mundial da Saúde.
} 
levando-os ao colapso e expondo a ausência de condições básicas de vida e saúde da maioria dos brasileiros,

Corrobora com a crise, o insuficiente conhecimento científico sobre o novo corona vírus, a sua alta velocidade de disseminação e capacidade de provocar mortes em populações independente de sexo, raça, cor e classe social, acirrando a crise política que o país enfrentava com o atual governo em suas rupturas internas que são exemplificáveis nas mudanças ocorridas no ministério da saúde, desvelando contradições de encaminhamentos protocolares no trato ao Covid19 e o esgarçamento institucional motivado, de forma mais visível pelas denúncias feitas pelo ministro da justiça ao pedir para sair do governo.

Nesse contexto, a expansão do Covid 19 para as áreas mais vulneráveis aumentou a incerteza, sobre quais seriam as melhores estratégias a serem utilizadas para o enfrentamento da pandemia epidemia. De acordo com WERNECK (maio de 2020) pode-se esquematizar de forma simplista, a resposta à pandemia do Covid19, numa subdivisão de quatro fases: contenção, mitigação, supressão e recuperação. $\mathrm{Na}$ fase de contenção seria o rastreamento ativo dos passageiros vindos do exterior e seus contatantes, visando a evitar ou postergar a transmissão comunitária, na segunda fase, de mitigação, inicia quando a transmissão sustentada da infecção já está instalada no país. O objetivo aqui é diminuir os níveis de transmissão da doença para os grupos com maior risco de apresentarem quadros clínicos graves, além, claro, do isolamento dos casos positivos identificados; na terceira fase, de supressão pode ser necessária quando as medidas anteriores não conseguem ser efetivas, seja porque sua implementação não pode ser concretizada de forma adequada e imediata (p.ex.: insuficiência de testes diagnósticos necessários para identificar indivíduos infectantes logo no início da epidemia) ou porque a redução alcançada na transmissão é insuficiente para impedir o colapso na atenção à saúde. E a quarta fase, de recuperação, quando há sinal consistente de involução da epidemia e o número de casos se torna residual. Essa última fase requer uma organização da sociedade para a reestruturação social e econômica do país. E, certamente, intervenção do Estado.

Nos estado do Amazonas e Roraima Brasil, os desafios são ainda maiores, pois pouco se sabe sobre as características de transmissão da Covid19 num contexto de grande desigualdade social, com populações vivendo em condições precárias de habitação e saneamento, sem acesso sistemático à água e em situação de aglomeração.

O texto que segue em sua completude trata de narrativas elaboradas a partir de várias ações abstraídas de sucessivas ações correlatas à pandemia por Covid 19 na realidade empiricamente dada. Essas narrativas foram organizadas pelas autoras neste artigo subdividido em: Introdução. Metodologia. Narrativas da pandemia motivada pelo covid 19 no estado do Amazonas. Narrativas da pandemia pelo Covid 19 em Roraima. Narrativas Fronteiriças. Conclusão.

\section{METODOLOGIA:}

O estudo consiste em uma pesquisa exploratório-descritiva de natureza quantitativa do tipo transversal, realizada a partir dos dados divulgados nos boletins das secretarias de saúde, do Sistema Único de Saúde - SUS, da secretaria de saúde indígena e nos boletins dos distritos sanitários especiais indígenas dos estados do Amazonas e Roraima. As narrativas que compõem o artigo foram coletadas em livros, artigos disponibilizados na internet e informados no final deste mesmo artigo, no item reservado às nas referências. 
O desenvolvimento do estudo ainda obteve informações nos sistemas de informações das prefeituras e Comissões de Combate ao novo corona vírus do Alto Solimões, de São Gabriel da Cachoeira e de Manaus, principalmente.

O diagnóstico situacional da covid 19 nos estados citados revela a busca por melhores estratégias de adoção para solucionar o problema, através das seguintes fases: levantamento de dados; análise dos dados obtidos e o estabelecimento de prioridades para composição do artigo, buscando através das narrativas elucidar e articular de forma teórica as práticas dos dados obtidos, de tal maneira que a percepção crítica do processo de ação e investigação da realidade contribua com novas narrativas, com vista à melhoria da realidade e dos processos nos quais a pesquisa foi desenvolvida (SARMENTO; CASAGRANDE, 2014).

Os estados mencionados ao longo deste estudo compõem a região norte do estado brasileiro, trata-se de uma região rica, mas, com problemas de acesso, porém com possibilidade para o estabelecimento de uma logística que atenda de forma compotente as populações nos locais remotos e inóspitos.

Tanto o Amazonas, quanto o estado de Roraima abarcam regiões carentes de muitos serviços e com indicadores ainda a serem suplantados, como o baixo Índice de Desenvolvimento Humano (IDH). Não obstante, quando se trata da totalidade, o estado do Amazonas tem IDH de 0,674 (considerado médio segundo o IBGE) e Roraima o IDH é de 0,707 (considerado alto). O Índice de Desenvolvimento Humano é uma medida comparativa de riqueza, alfabetização, educação, esperança de vida, natalidade e outros fatores para os diversos países do mundo.

Para a investigação da realidade regional acerca do problema, foi elaborado um instrumento referente ao diagnóstico situacional das notificações diárias divulgadas pelas secretarias referente ao Covid 19. O instrumento norteou a coleta de dados para a compreensão do problema, e sua elaboração levou em consideração indicadores prioritários descritos no site do Ministério da Saúde e do UNA-SUS - Fiocruz. Por meio deste site Fiocruz - UNA-SUS obteve-se dados dos serviços oferecidos pelo Sistema Universidade Aberta do SUS, estabelecido pelo Decreto n $^{\mathbf{0}} 7.385$ de 08 de dezembro de 2010. Esses serviços são: Acervo UNA-SUS, Webportfólio, Comunidades Virtuais e Ambientes Virtuais de Aprendizagem que visa fortalecer e qualificar as ações de vigilância em saúde em todos os estados e municípios do Brasil e contém indicadores específicos para a o combate à pandemia.

\subsection{NARRATIVAS DA PANDEMIA MOTIVADA PELO COVID 19 NO ESTADO DO AMAZONAS.}

O termo pandemia que significa alta taxa de contaminação, motivou a Organização Mundial da Saúde - OMS, no dia 11 de março de 2020 a decretar estado de pandemia pelo novo Corona Vírus, que desencadeia a doença que convencionaram chamar de Covid 19. Na definição da OMS, pandemia é a disseminação mundial de uma nova doença. O termo é utilizado quando uma epidemia ou um grande surto que afeta uma região se espalha por diferentes continentes com transmissão sustentada de pessoa para pessoa. Éi exatamente o que acontece atualmente com o novo coronavírus, identificado originalmente na cidade de Wuhan, na China. A covid19, causada pelo Sars-CoV-2 (o novo coronavírus) está hoje em mais de 115 países.

A pandemia reduziu a discussão da crise sanitária e do acesso à saúde com qualidade em discussões sobre isolamento vertical e horizontal, se o uso da máscara seria pertinente ou não, sobre a eficácia da desinfecção dos espaços públicos, ou seja, uma série de providências necessárias, que não foram realizadas, aprofundando a crise sanitária e agregando a mesma na crise política e social. 
De acordo com a análise do economista SALAMA (maio de 2020) É uma crise que pede renovação completa da maneira de pensar a economia e a política. Hoje, a solidariedade tem primazia, embora, infelizmente, não na América Latina, nos Estados Unidos e em alguns outros países. Amanhã, quando as condições sanitárias permitirem, será a hora de voltar ao trabalho e o autor espera que a solidariedade se mantenha e que o modelo econômico não consista em uma retomada do anterior, se não a história se repetira como tragédia...

Em 13 de março de 2020 o estado do Amazonas confirmou o primeiro caso de Covid 19, e ao procederem com os protocolos da contenção dezenas de pessoas procuravam atendimento em prontos socorros públicos e privados, sem a devida precaução. A contaminação proliferou-se e antes da conclusão da identificação de uma viajante de 39 anos que chegou de Londres e de um casal que esteve no mesmo vôo do viajante que chegou da Itália em São Paulo, eclodiam notícias na mídia sobre o aumento repentino das "internações por problemas respiratórios", o primeiro óbito foi registrado em 24 de Março, sendo a vítima um empresário do município de Parintins.

Em um mês o estado do Amazonas, a partir de sua capital Manaus alçou ao quarto estado em contaminados e o terceiro em óbitos, em 13 de Abril, o Amazonas tinha 1.206 casos de contaminados e 62 mortes.

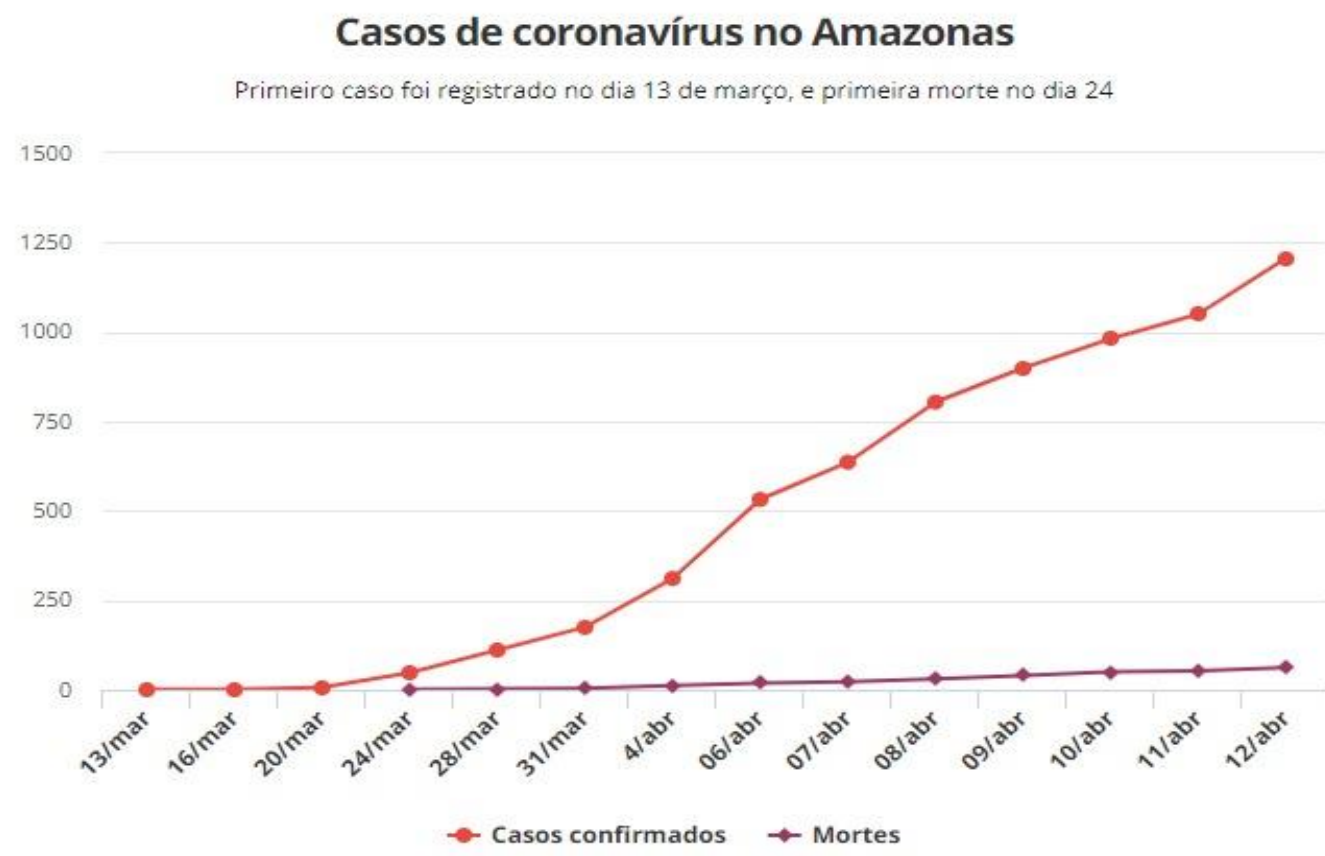

Fonte: FVS-AM

Para conter o avanço da doença, o governador e os prefeitos dos municípios do Amazonas decretaram medidas como suspensão de aulas, cancelamento de eventos para evitar aglomeração de pessoas, fechamento de rodovias, proibição de comércio não essencial, toque de recolher, entre outras, após vinte e quatro dias da confirmação do primeiro caso de contaminação e treze dias, após o primeiro óbito. A operação "Fique em Casa" teve início dia 06 de Abril, com o intuito de intensificar a fiscalização de comércios que descumpram a medida.

As recomendações das autoridades estaduais e municipais, quando aos cuidados sanitários para além da higiene das mãos foram pouco céleres. Inicialmente negavam a eficácia do uso da 
máscara confundindo a população que assistia os noticiários nos quais alertavam sobre a importância desse equipamento de proteção individual, não providenciaram a desinfecção dos espaços públicos; enquanto a população via nas principais cidades do mundo ser desinfectadas. Todas essas ações desenvolvidas como profilaxia, de certo teriam evitado a dimensão que chegou a pandemia na capital amazonense.

Até que representantes institucionais estaduais e municipais levassem à população as orientações devidas os casos de Covid 19 tinham aumentado absurdamente e nos últimos quinze dias de Abril; noticiaram a superlotação nos hospitais e unidades de saúde de Manaus, antes já precária e com poucas condições sanitárias nos locais de atendimento.

A cidade também conhecida como a Paris dos Trópicos pela magnitude arquitetônica de prédios públicos, em particular, do Theatro Amazonas (T.A) tornou-se foco de atenção nacional e internacional, pela forma como a pandemia alastrou-se e pelo número de óbitos, causando além do colapso dos leitos hospitalares, o esgotamento dos espaços nos principais cemitérios da cidade.

Em nível nacional Manaus é objeto de reportagens com inúmeras denúncias, desde a limitada condição de atendimento, ausência de equipamentos de proteção individual para os profissionais de saúde e usuários até o superfaturamento na compra de respiradores e contratos de hospital privado para suprir necessidade de atendimento de responsabilidade do poder público, conforme o Programa Conexão Repórter do SBT, exibido em 27 de Abril de 2020, com cenas dos descasos das instituições e da superlotação do cemitério Nossa Senhora Aparecida (Tarumã), com sepultadores (nominados popularmente de coveiros) realizando sepultamentos em covas coletivas, conforme registro fotográfico de Alex Pazuello da SEMCOM, publicado também no Amazonas Atual em 24/05/2020.

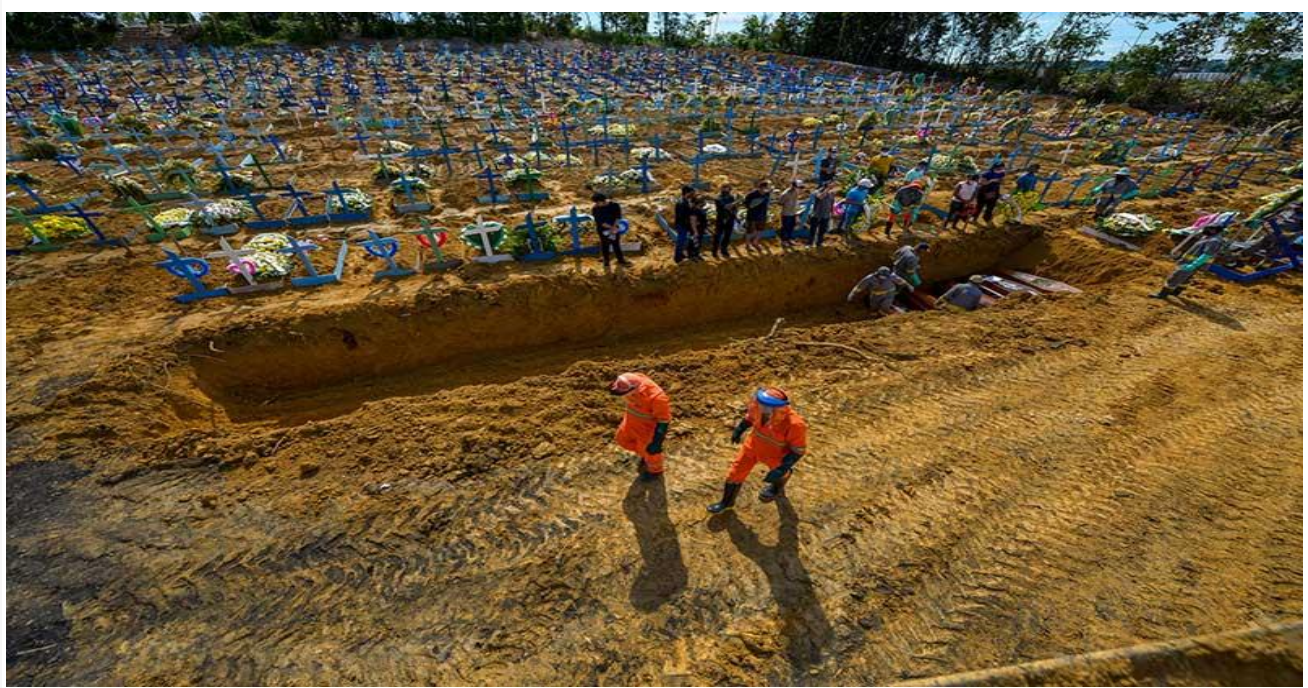

Mortes por coronavírus supera em dois meses os óbitos de todo o ano de 2019 (Foto: Alex Pazuello/Semcom)

Ainda em Abril exatamente dia 10 houve o anúncio do esgotamento da capacidade operacional do HPS Delphina Aziz, referência para internação de casos graves do novo Covid 19, a unidade de acordo reportagens televisivas e impressas, não possuía equipe médica para atender os outros nove leitos disponíveis, além de não contar nos leitos disponíveis os equipamentos necessários para o tratamento da doença, em pauta.

As notícias da escassez de mão-obra especializada na área da saúde motivou as duas universidade públicas a agilizarem colações de grau. A Universidade Federal do Amazonas UFAM, que havia como ação profilaxia radical suspender as atividades e instrúíndo os seus agentes públicos a permanecerem em casa, antecipou a colação de grau de médicos, enfermeiros, farmacêuticos e fisioterapeutas, em atenção ao chamado do Programa do Governo 
Federal "O Brasil Conta Comigo" (Portal UFAM www.ufam.edu.br ). E a Universidade do Estado do Amazonas - UEA antecipou a colação de grau de médicos, enfermeiros e farmacêuticos, (Portal A Crítica www.acritica.com.br), ambas com a mesma finalidade, suprir a demanda para atender vítimas do Covid 19.

O conjunto das ações realizadas e os esforços da sociedade civil e política não estancaram os óbitos em Manaus que chegou a ter em 24 horas entre os dias 05 e 06 de Maio o registro de 69 óbitos, ao se considerar as subnotificações esse número pode ultrapassar para mais de 100 óbitos por dia, de acordo com a Agência REUTERS de 08/05/2020 (https://amazonia.org.b). E conforme matéria de Julie Pereira publicada no jornal eletrônico Amazonas ATUAL de 24 de Maio, dois meses após a primeira morte pelo Covid 19 quase duas mil pessoas também foram vítimas da doença e 1.744 óbitos foram registrados até esse sábado, 23 de Maio.

A quantidade de mortos põe o estado em sexto lugar no número de mortes pelo novo corona vírus no país. Em $1^{\circ}$ de Maio de 2020, o Governo do Estado do Amazonas inaugura leitos para tratamento intensivo ( UTI) no Hospital Nilton Lins e nesse mesmo hospital uma Ala para o atendimento à população indígena, que sofre com o descaso de assistência à Saúde Indígena e invisibilidade nos registros de atendimento e óbitos.

Os indígenas em situação de vida urbana de Manaus realizaram manifestações para denunciar não somente o descaso, mais também, o avanço do Covid 19 em suas áreas mais remotas, fica o registro dos inúmeros casos de contaminação e óbitos que atingiram os kokama, em particular, os residentes no Parque das Tribos (Tarumã).

A pandemia pelo Covid 19 no Estado do Amazonas de 13 de Março a 31 de Maio de 2020, motivou, 41.358 casos confirmados mais 818 que aguardam resultados de exames e 2.052 óbitos. Desvelando para o mundo a abismal desigualdade social e crise sanitária sem precedente na história e que e avançou num rápido processo de interiorização, alcançando o Alto Solimões que registrou até dia 31 de Maio de 2020, centenas de caso de contaminação e óbitos, somente em Bejamin Constant foram contabilizados mais de 800 pessoas contaminadas, com alerta para as subnotificações

No que se refere às populações indígenas residentes em Manaus registra-se neste artigo que até dia 31 de Maio não consta nos formulários das unidades de saúde, em especial, dos hospitais credenciados para o atendimento do Covid 19, Unidades Básicas de Saúde e Unidades de Pronto Atendimento, um item que possa identificar se o paciente é indígena ou quilombola, o que acentua os casos de subnotificações quando da mortes desses dois segmentos populacionais.

A narrativa de que a identificação do paciente como índio ou quilombola subtrai o quantitativo de brasileiro, não cabe mais. Sabe-se que todos são brasileiros e que Constituição Federal assegura a direitos ambas populações, reconhecendo a diversidade populacional do país; além do que o Brasil signatário da Organização Internacional do Trabalho, OIT, em suas Resoluções de 1.957 e de 2004, esta última garante a organização das populações mencionadas nos espaços urbanos portanto, não há o que se discutir, e sim, de cumprir-se com a lei.

Em regiões com maior $n^{0}$ de indígenas, como Alto Solimões e São Gabriel da Cachoeira, os DSEI'S conseguem inserir demandas e ganham visibilidade mesmo não constando sua etnia, conseguem ser identificados como indígenas. Conforme mostra os boletins abaixo: 


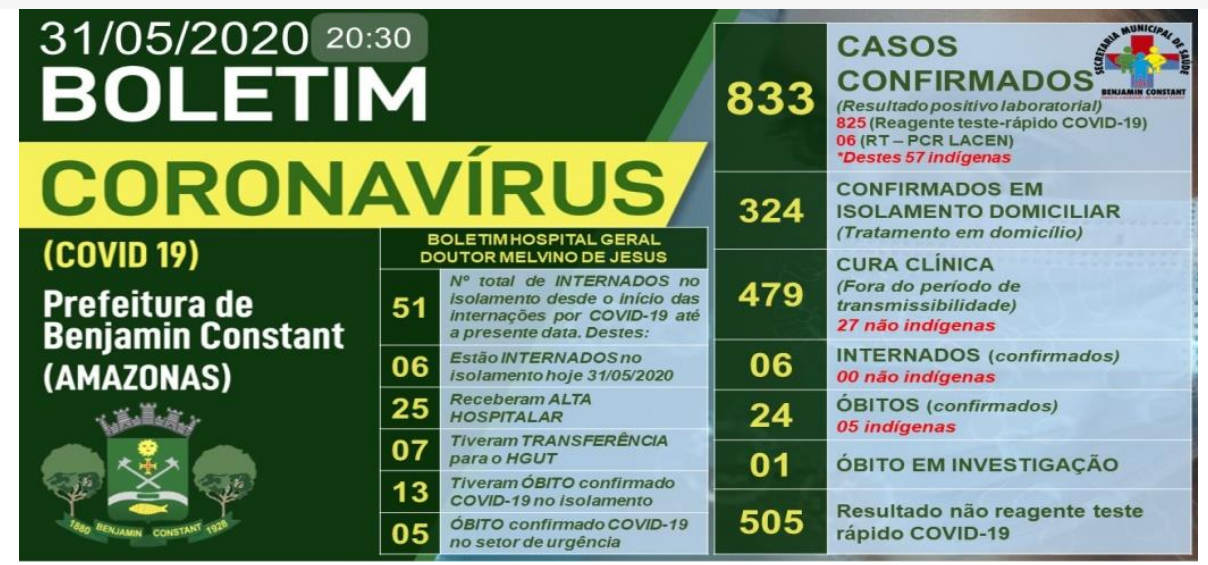

Boletim coletado por Gleissimar Castelo Branco. Grupo EPPPAC. 31 de Maio de 2020.

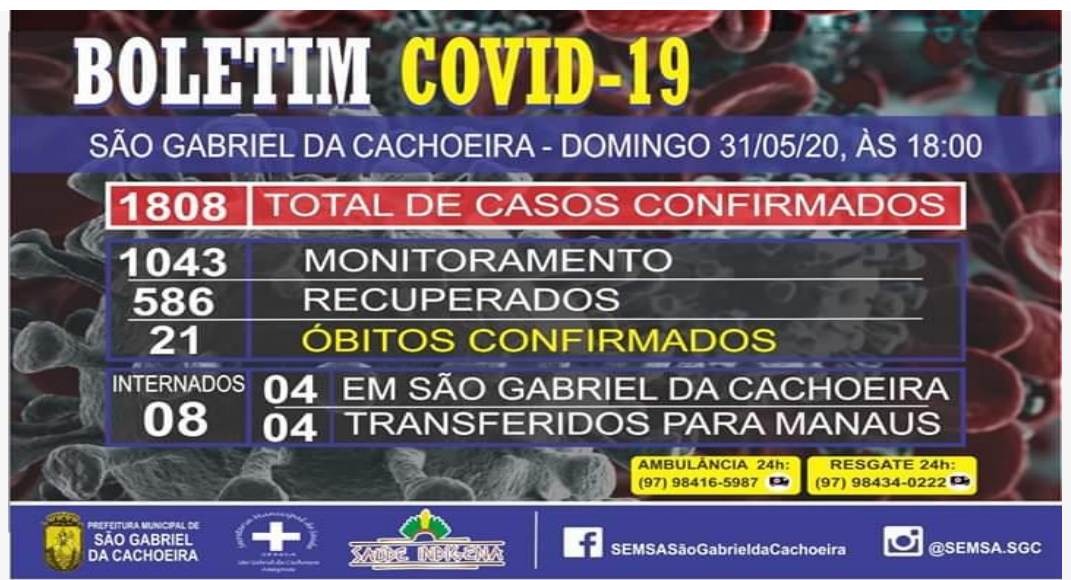

Boletim coletado por Priscila Rocha Santos, membro do GPQSSS e EPPPAC. 31 de Maio de 2020

E os boletins dos DSEI'S do Alto Solimões e de São Gabriel da Cachoeira, bem como do DSEI MANAUS, também podem ser acessados diariamente na página da Secretaria Especial de Saúde Indígena - SESAI - www.saudeindigena.gov.br

O Estado do Amazonas fecha o mês de Maio com a mácula de ser destaque nacional pela quantidade de pessoas contaminadas e de óbitos, como registrados no Boletim abaixo, e de ser o estado com o maior $n^{\circ}$ de indígenas que padecem duplamente: pelo preconceito que os faz invisíveis e pela vulnerabilidade orgânica resultado dos enfrentamentos dos diversos ciclos econômicos que subtraíram seus espaços impossibilitando-os daquilo que lhes é culturalmente determinado, ou seja, o auto isolamento em situação de doenças graves e debilitaram seus organismos e hábitos, tornando-os frágeis às diversas viroses. 


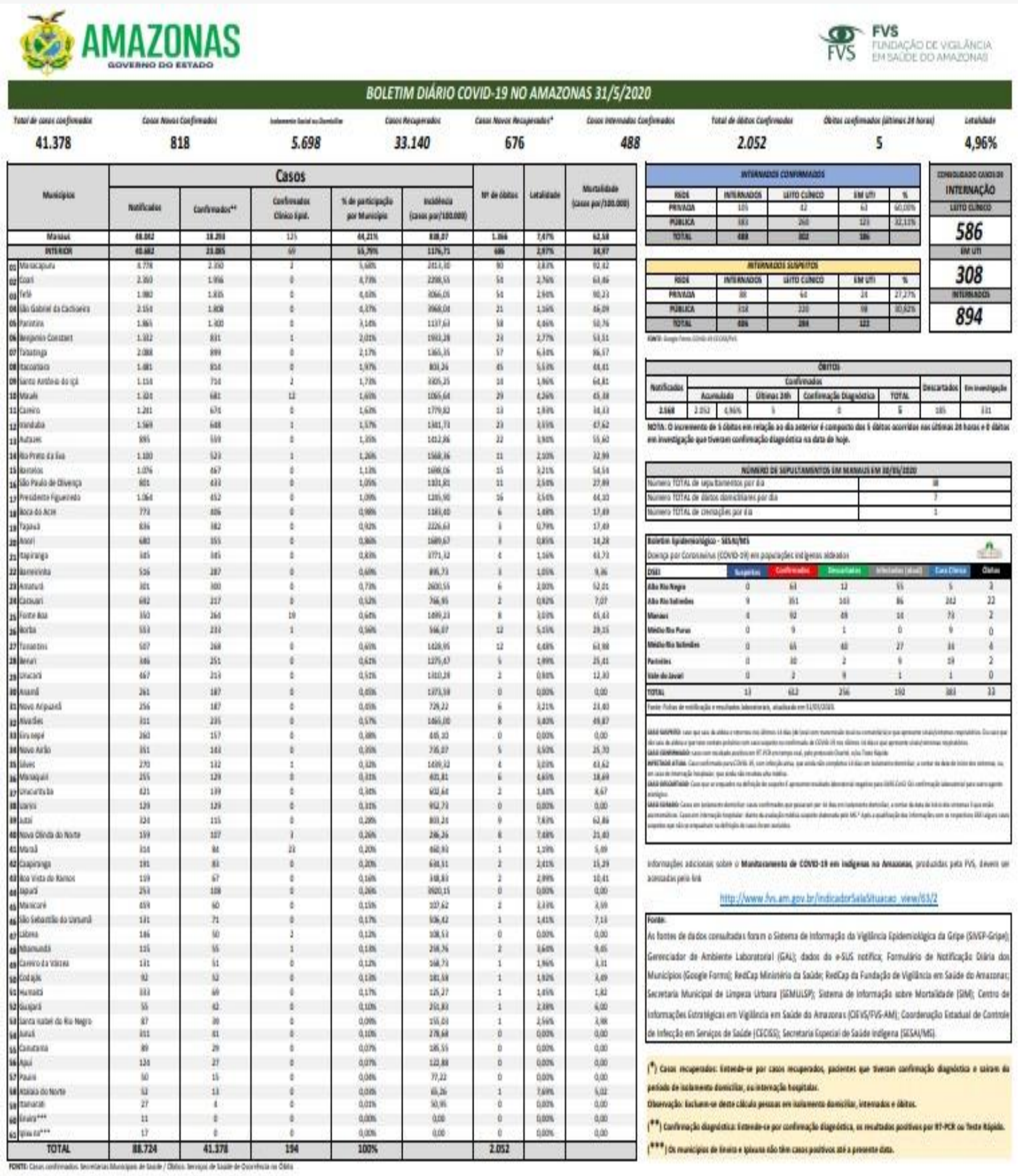




\subsection{NARRATIVAS SOBRE A PANDEMIA PELO COVID - 19 EM RORAIMA;}

A análise situacional realizada no estado de Roraima a partir das diversas narrativas responde ao objetivo do texto de propiciar "uma mirada" em parte da região norte, a partir de dois estados que fronteiriços, que tem suas capitais Manaus e Boa Vista ligados pela rodovia BR !74, conhecida como Manaus-Boa Vista e que interliga esses estados aos estados do Mato Grosso, Rondônia e todos à Venezuela, O estado de Roraima, também tem fronteira com a República da Guaina, portanto, Boa Vista é uma porta aberta a intenso trânsito e possível circulação do Covid 19, exemplar da globalização e movimentação de pessoas.

No desencadear reflexivo das narrativas sobre a conjuntura global e os efeitos provocados pelo Covid-19, enquanto um tema atual, emergente e de grande repercussão, procedeu-se com a imersão nas ciências sociais, buscando compreender a propagação e os efeitos da pandemia na sociedade, abstraindo das formas clássicas de aplicação da análise de narrativas na comunicação cotidiana e da sociologia, como ensina SCHÜTZEL (2014) é concebível que se possa identificar constelações de interesses e um cerne de aptidões sociais, tanto gerais quanto vinculadas a determinados assuntos, por meio do processamento retrospectivo das próprias experiências de ação em narrativas orais espontâneas. Com efeito, para analisar a problemática tornou-se necessário a articulação teórica entre as Ciências Sociais e as Ciências da Saúde. Dessa perspectiva, a interdisciplinaridade que atravessa este artigo é um elemento essencial na discussão em foco.

Nesse contexto, o novo Coronavírus e a doença que é transmitida, o Covid 19 é considerado como um "fato social total”, um conceito do sociólogo e antropólogo Marcel Mauss (2003), "é uma atividade que tem implicações em toda a sociedade, nas esferas econômicas, jurídicas, políticas e religiosas" para se referir a esses fenômenos que colocam em jogo a totalidade das dimensões sociais.

Ao se apontar a discussão para o estado de Roraima, convencionou-se abordar com aporte em Milton Santos (2006) o conceito de "espaço" como um fato social, produto da ação humana, uma natureza socializada que, por sua vez, interfere no processo social não apenas pela carga da historicidade passada, mas também pela carga inerente de historicidade possível de ser construída, na medida em que é a instância de determinação no movimento real, de transformação. Seria a ação humana e a ideia de movimento, numa acepção da dialética marxista. O espaço relaciona-se à incorporação do trabalho humano na superfície terrestre e no caso da narrativa proposta, o trabalho refere-se ao executado nos hospitais, unidades básicas de saúde, unidades de pronto atendimento etc.

Com a propagação da pandemia se avolumam as notícias na mídia de hospitais lotados, sem recursos humanos, respiradores, medicamentos e testes laboratoriais que venham corresponder a necessidade da população e a precariedade do trabalho do profissional de saúde.

Nesse contexto, o CEEN ${ }^{3}$ aponta que a incidência do Covid 19 no Brasil é preocupante. Com efeito, é sabido que a saúde pública do país e o seu sistema de atendimento são modelos de referência no mundo inteiro, O SUS (Sistema Único de Saúde) tem como base a integralidade, a universidade e a equidade dos pacientes e trabalhadores, um direito de todos os cidadãos. Entretanto ao longo da história de sua consolidação, o sistema público foi deixado de lado, sem

\footnotetext{
${ }^{3}$ Centro de Estudos.
} 
investimentos adequados, não suportando já a vários anos a demanda da sociedade pelos serviços de saúde. Segundo Diniz e Carino (2020) do jornal El País argumentam que a Epidemia do vírus Corona parece uma atualização das aulas de Michel de Foucault sobre biopolítica, segurança e territórios. A biopolítica é o poder que organiza as políticas da vida, isto é, são táticas que regulam que corpos devem viver e quais podem ser descartáveis. A explosão de uma epidemia é um momento efusivo a biopolítia: em nome de proteção coletiva controla os corpos, se traçam fronteiras reais ou imaginarias a saúde.

O estado de Roraima não foge à regra da crise na saúde pública brasileira, agravada pela Pandemia. Historicamente, tudo começou com duas pessoas que viajaram para São Paulo, o epicentro da doença e ao regressarem testaram positivo ao coronavírus, no dia 21 de março. Nesse contexto, a primeira vítima a falecer foi um idoso de 61 anos no dia 3 de abril de 2020 no Hospital Geral do Estado, o histórico conta que o referido paciente havia passado férias em Fortaleza. O paciente foi diagnosticado positivo para COVID - 19, com comorbidades associadas, como diabetes e hipertensão. Nesse período o boletim da secretária do estado de saúde, apontava 30 casos confirmados. Antes dessa confirmação, o estado tinha 16 casos suspeitos. Com efeito, passados em torno de 30 dias, a Secretária de Saúde de Roraima apresenta 247 casos confirmados da doença e 3 óbitos. Se evidencia aí a velocidade do crescimento atingindo a população, em 18 de maio Roraima registra 60 óbitos por Covid-19. A mais nova atualização em 25 de junho pela Secretaria de Saúde do Estado de Roraima registrou 4.220 casos notificados, 2.583 casos confirmados, 168 pacientes internados, 712 recuperados, 116 altas hospitalares e 102 números de óbitos.

Tabela 1 - Casos confirmados de coronavírus por municípios.

\begin{tabular}{ccccc}
\hline MUNICIPIOS & NOTIFICADOS & CONFIRMADOS & RECUPERADOS & DESCARTADOS \\
\hline Alto Alegre & 99 & 58 & 1 & 31 \\
Amajari & 41 & 29 & 1 & 12 \\
Boa Vista & 3.229 & 1.997 & 611 & 1.119 \\
Bonfim & 132 & 67 & 8 & 65 \\
Cantá & 124 & 95 & 7 & 29 \\
Caracaraí & 18 & 15 & 0 & 3 \\
Caroebe & 128 & 49 & 17 & 79 \\
Iracema & 11 & 6 & 0 & 5 \\
Mucajaí & 127 & 62 & 6 & 65 \\
Normandia & 22 & 6 & 0 & 6 \\
Pacaraima & 145 & 94 & 4 & 51 \\
Rorainópolis & 150 & 117 & 39 & 33 \\
S. J. da Baliza & 54 & 20 & 0 & 34 \\
São Luiz & 67 & 36 & 16 & 31 \\
Uiramută & 2 & 1 & 0 & 1 \\
Outros & 38 & $30^{*}$ & 2 & 12 \\
\hline TOTAL & 4.388 & $\mathbf{2 . 6 8 2}$ & $\mathbf{7 1 2}$ & $\mathbf{1 . 6 8 6}$ \\
\hline
\end{tabular}

Fonte: Gerenciador de Ambiente Laboratorial/GAL - LACEN/RR. Dados atualizados em 26/05/2020 às 17:00. Dados sujeitos à revisão.

No que tange ao setor econômico, podemos perceber o aumento do desemprego e consequentemente da pobreza. Esse fator vem influenciando as mais diversas camadas sociais. Vale ressaltar que Roraima apresenta uma economia incipiente e em estágio de formação. Diante do panorama que se apresenta, por um lado procura-se preservar vidas, por outro com o fechamento do comércio e serviços não essenciais vincula-se ao agravamento do desemprego, junto ao quadro econômico recessivo do Brasil. 
Nessa discussão frente a presente gravidade da situação da saúde pública, o estado de Roraima realizou a suspensão das aulas no estado como medida de prevenção. A Prefeitura Municipal de Boa Vistas recomendou a suspensão de missas, cultos religiosos e proibiu de shows em bares e restaurantes atividades de lazer. A Universidade Federal de Roraima suspendeu as aulas. O Presidente do Brasil determinou o fechamento das fronteiras com Venezuela e Guiana, afetou os municípios de Pacaraima e Bonfim que fazem fronteiras com Venezuela e Guiana.

Convém destacar que na capital do estado de Roraima, município de Boa Vista, os primeiros casos de contaminação ocorreram nos bairros de melhor IDH $^{4}$ da cidade, os infectados haviam realizado viagens para outros estados. Atualmente o vírus já atingiu a periferia da cidade, as pessoas mais vulneráveis. De acordo com o mencionado no texto, a estrutura hospitalar existente é incapaz de atender a demanda na situação de pico da doença. Hospitais de Campanha foram construídos, realização feita entre a parceria do Exército, Governo Estadual e a Prefeitura de Boa Vista (Capital de Roraima). Até o presente momento o referido hospital, em pleno funcionamento devido à falta de profissionais da saúde e equipamentos. O Hospital Geral de Roraima é o único da capital que atende os pacientes com a Covid-19. E dos 38 leitos de UTI, quase todos estão ocupados. A presidente do Conselho Regional de Medicina (CRM), doutora Rosa Leal, chamou a atenção para a situação crítica do estado e diz que faltam equipamentos para a proteção dos profissionais de saúde e pacientes.

Os casos de coronavirus disparam na cidade Boa Vista após a taxa de isolamento despencar em $20 \%$, passando de $60 \%$ para $40 \%$. O ideal é uma taxa de $70 \%$ de isolamento, para que dessa formar seja evitado o colapso no sistema público de saúde. Roraima atravessa um dos piores momentos da pandemia, considerando ainda que o estado está no período de inverno, marcado por diversas doenças respiratórios além de dengue e gripe.

\footnotetext{
${ }^{4}$ Índice de Desenvolvimento Humano.
} 
Mapa 1 - Casos confirmados de COVID-19 em Boa Vista.

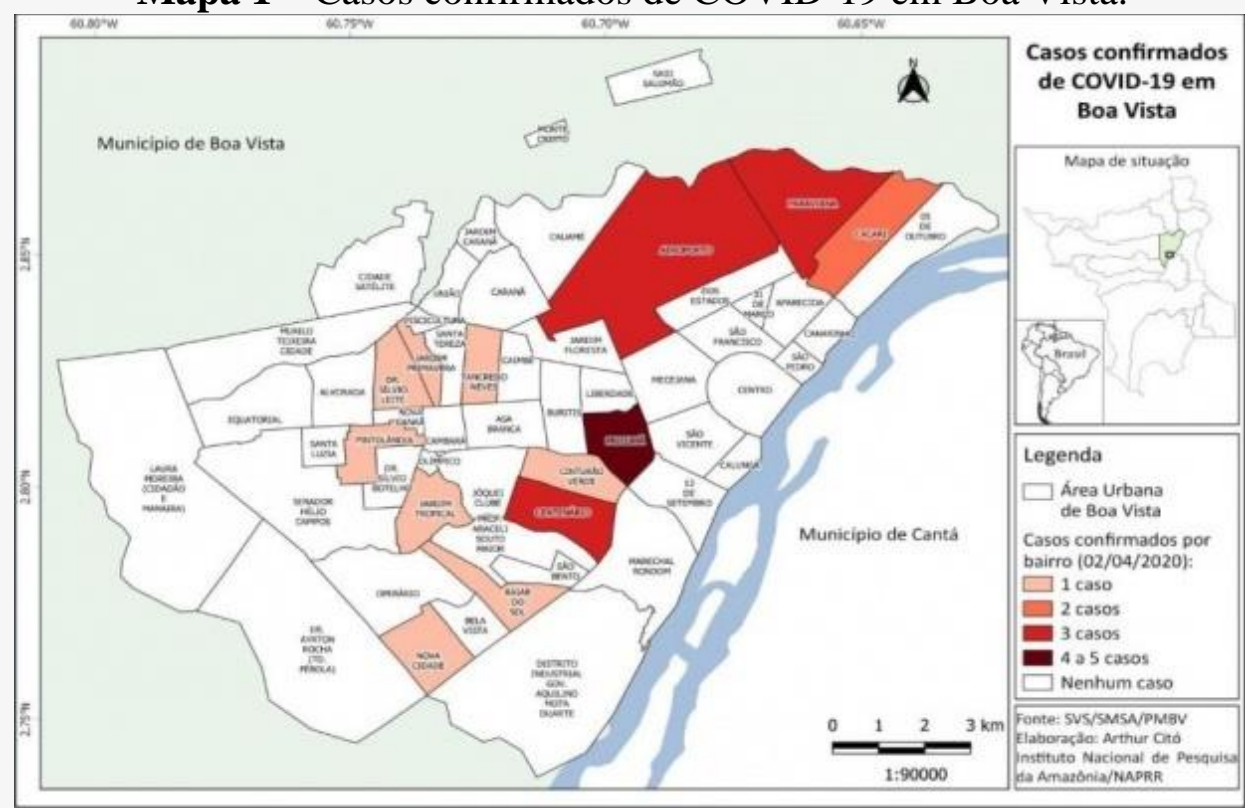

Fonte: Folha de Boa Vista (online), 07/04/2020. Disponível em:

https://folhabv.com.br/noticia/CIDADES/Capital/13--bairros-tem-casos-confirmados-de-Coronavirus-em-BoaVista/64472

De acordo com a prefeita da cidade de Boa Vista - RR, Teresa Surita, os cinco novos bairros da capital registraram casos de Covid-19 nesta semana. Com isso, 48 dos 56 bairros registraram pacientes com a doença, o que representa $85 \%$ da área urbana. O Jornal Roraima em Tempo mostrou na última terça-feira (28), que outras 11 regiões tinham entrado para a lista vermelha. Acima de 30 casos temos Paraviana e 13 de setembro. Seguido do São Vicente e Pricumã. Seria uma irresponsabilidade flexibilizar mais do que foi feito até aqui, ponderou a prefeita. A gestora ainda destacou as medidas tomadas até o momento, para evitar a propagação ainda maior do Covid-19, tornou obrigatório o uso de máscaras no comércio e órgãos públicos da capital.

\subsection{UMA MIRADA SOBRE A PANDEMIA POR COVID 19 NOS PAÍSES FRONTEIRIÇOS DOS ESTADOS DO AMAZONAS E RORAIMA.}

Na América Latina, a lista de pessoas mortas pelo COVID-19 é liderada pelo Brasil, com 6.329 vítimas (dados de Maio de 2020). O México segue, com 1.859; O Peru, com 1124, o Equador, com 1.063, e a Colômbia, com 314, de acordo com a plataforma Worldometer, (dados acessados em 31 de Maio de 2020 -https://www.trt.net.tr/portuguese/america-latina).

Com parte do seu território na Amazônia, a Colômbia desenvolveu as quatro etapas, a saber: contenção, mitigação, supressão e recuperação, mencionadas na introdução deste trabalho, de forma a evitar a proliferação em alta escala do Covid 19. Todavia, as cidade de Barraquilla, Tumaco e Letícia que é a capital colombiana do distrito Amazonas, vizinha de Tabatinga disparou em casos e culpa o governo brasileiro de não ter efetuado os protocolos de profilaxia orientados pela OMS na cidade de Tabatinga. Sob reclamos autoridades colombiana acusam o governo brasileiro por terem permitido que o Covid 19 avançassem sobre o Amazonas, o que refletiu no aumento dos casos da pandemia em território colombiano. Letícia apresenta o maior número de casos de contaminados e mortos pelo Covid 19 no país, em pauta. 


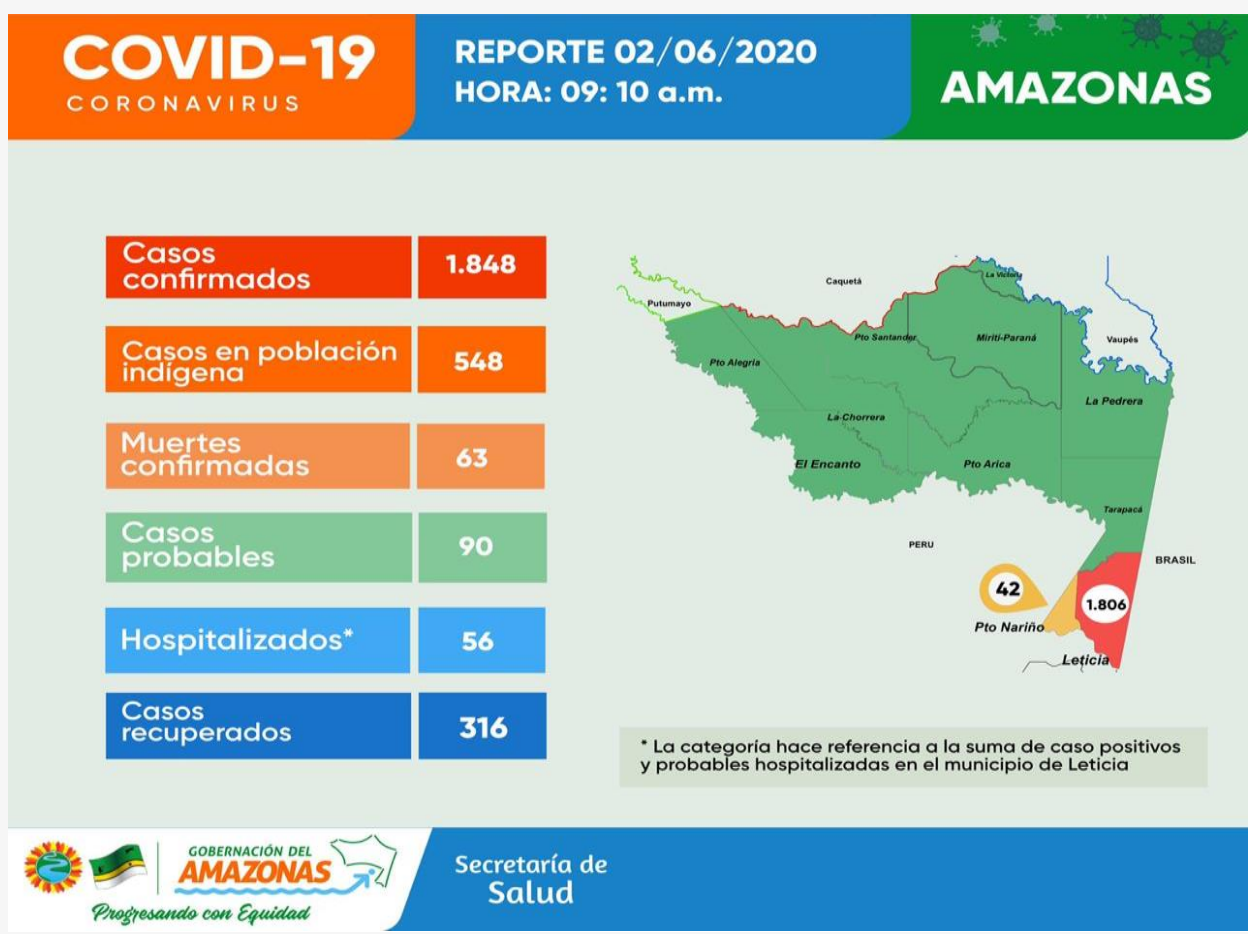

Enviado Por Gleissimar Castelo Branco. Grupo EPPPAC

A Ilha de Santa Rosa pertencente ao Peru que compõe a tríplice fronteira, considerada área frágil tem resistido com barreira sanitária rígida e assistência através da Igreja Católica, de acordo com o Blog Jambo Verde https://jamboverde.blogspot.com/2020/06/leticia-entre-as-3cidades-do-pais. O Peru em Maio contabilizou 174.884 casos e 4.767 mortes, percebeu-se nos boletins e nas mídias consultadas que em Abril de 2020, o Peru era o segundo lugar em casos do Covid 19; como acúmulos de doentes e falta de leitos na U.T.I, em Santa Rosa, o país conseguiu avançar no controle e até 22 de Maio em todo país apresentou os dados supra registrados.

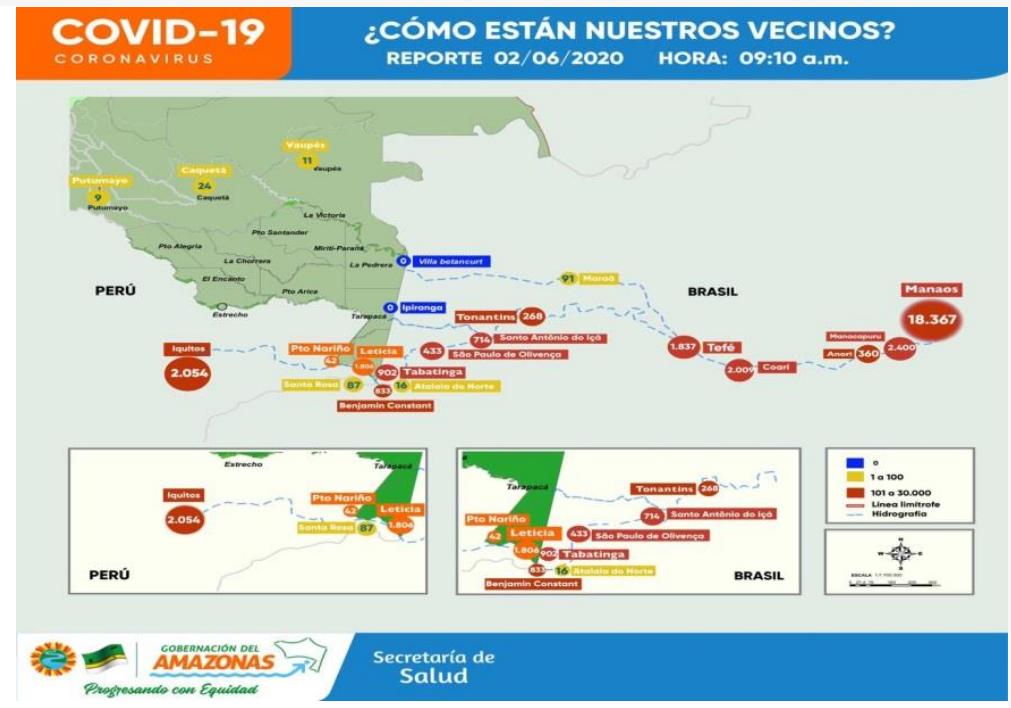

Enviado Por Gleissimar Castelo Branco. Grupo EPPPAC 
Os últimos números do governo colombiano também detalham que nas últimas 24 horas foram registrados 499 novos casos de infecções, elevando o número total de pacientes infectados para 7.006. No caso de Letícia, o monitoramento rigoroso será realizado até 15 de junho, com uma estratégia de triagem, apoiada pelo Instituto Nacional de Saúde, daquele país. Além disso, devem ser mantidas as atuais medidas sanitárias de isolamento preventivo obrigatório, sem as aberturas adicionais estabelecidas no Decreto 749, de 28 de maio de 2020.

O Peru que ocupa o segundo lugar em casos do Covid 19 na região, porém, apresenta números muito baixo, diferença abissal em relação ao primeiro colocado que é o Brasil, como verificado. O Brasil como o $4^{\circ}$ país com o maior $\mathrm{n}^{\mathrm{o}}$ de casos do mundo, fechando o mês de Maio de 2020 com mais de trinta mil mortes.

Venezuela: O país faz fronteira com o Amazonas com o município de São Gabriel da Cachoeira, região do Alto Rio Negro/Brasil e com o estado de Roraima/Município de Pacaraima, com poucas narrativas, até 13 de Maio de 2020 tinha 1(dez) mortes e 423 casos. Ainda na primeira fase das providências exigidas pela OMS, o país suspendeu os vôos e fechou as fronteiras.

República da Guiana: O país faz fronteira com o estado de Roraima/Município de Bonfim, apresentou até Maio de 2020, de acordo com dados oficiais publicados, até 29 de Maio de 2020 436 casos confirmados, 161 pacientes recuperados e 1 morte.

\section{CONCLUSÃO}

Por fim, a pandemia de Covid-19, traz repercussões não apenas na área das ciências médicas epidemiológica, mas repercussões sociais, econômicas, políticas, culturais e históricas sem precedentes na história recente. Faz-se necessário ações para contenção da doença. Precisamos responder aos desafios colocados pela pandemia, através de uma rede de pesquisadores no campo das ciências sociais e médicas, dar repostas e capacitação de estratégia para o enfrentamento do Covid-19. Em Roraima, as perspectivas em relação ao coronavírus não são favoráveis, dado a inoperância governamental. Certamente, a sociedade necessita de um novo paradigma tecnológico organizacional para enfrentar os diversos problemas, como o desemprego, a inflação, a recessão, as pandemias, as catástrofes naturais, etc. Urge a necessidade da conscientização da sociedade em relação a referida doença, no que tange ao isolamento social, quarentena, caso contrário continuarão a aumentar o caso em nosso estado.

Nessa empreitada, juntam-se todos os esforços necessários para proteger as pessoas, principalmente do grupo de risco. Tanto no Amazonas quanto em Roraima o momento é de implementar medidas agressivas e comprovadas de saúde pública através de planos de biosseguranças e viabilizadas pela biopolítica, que devem ter centralidade no mundo do trabalho e nas sociabilidades do "novo normal" para evitar mortes. A vida é o nosso maior bem.

\section{REFERÊNCIAS:}

BLOG JAMBO VERDE. Tríplice Fronteira do Alto Solimões. Maio 2020.Publicações enviadas ao grupo EPPPAC por Gleissimar Castelo Branco.

Centro de Estudos - CEEN. Os 6 maiores desafios que a saúde pública do Brasil vem enfrentando. Disponível em: <https://www.ceen.com.br/os-6-maiores-desafios-que-a-saude-publica-do-brasil-vemenfrentando/>. 
CENTRO DE INFORMAÇÃO ESTRATÉGICAS DE VIGILÂNCIA EM SAÚDE CIEVS RORAIMA. Boletim epidemiológico sobre a doença pelo Coronavírus 2019 (COVID-19). 26 de maio de 2020.

CORREIA, Cyneida. 13 bairros têm casos confirmados de Coronavírus em Boa Vista. Disponível em: <https://folhabv.com.br/noticia/CIDADES/Capital/13--bairros-tem-casos-confirmados-deCoronavirus-em-Boa-Vista/64472>. Acesso em: 27 mai. 2020

CORREIA, Cyneida. 13 bairros têm casos confirmados de Coronavírus em Boa Vista. Jornal Folha de Boa Vista (online). Disponível em: <https://folhabv.com.br/noticia/CIDADES/Capital/13--bairros-temcasos-confirmados-de-Coronavirus-em-Boa-Vista/64472>.

DESCONHECIDO. Organização Mundial da Saúde classifica novo coronavírus como pandemia. Disponível em: <https://nacoesunidas.org/organizacao-mundial-da-saude-classifica-novo-coronaviruscomo-pandemia/>. Acesso em: 27 mai. 2020

DINIZ, Debora; CARINO, Giselle. A necropolítica das epidemias, El País. 09 mar. 2020. Disponível em: <https://brasil.elpais.com/opiniao/2020-03-09/a-necropolitica-das-epidemias.html>. Acesso em: 27 mai. 2020

FERREIRA, Josué. Casos de coronavírus disparam em Boa Vista após taxa de isolamento despencar em 20\%. Disponível em: <https://roraimaemtempo.com/ultimas-noticias/casos-decoronavirus-disparam-em-boa-vista-apos-taxa-de-isolamento-despencar-em-20p,356823.jhtml>.

Acesso em: 27 mai. 2020

FIOCRUZ. Organização Mundial da Saúde declara novo coronavírus uma pandemia. Disponível em: $\quad<$ https://www.canalsaude.fiocruz.br/noticias/noticiaAberta/organizacao-mundial-da-saudedeclara-novo-coronavirus-uma-pandemia11032020>.

FUNDAÇÃO DE VIGILÂNCIA SANITÁRIA DO ESTADO DO AMAZONAS. www.fvs.am.gov.br e http://www.fvs.am.gov.br/transparenciacovid19 - acessados em 31/05/2020 e e/06/2020.

GAL - LACEN/RR. SESAU: Secretaria de Saúde. Disponível em: <saúde.rr.gov.br〉. Acesso em: 27 mai. 2020.

JORNAL ELETRÔNICO: AMAZONAS ATUAL de 224 de Maio. https://amazonasatual.com.br/acessado em $1^{\circ}$ de Junho de 2020.

MAUSS, Marcel. "Ensaio sobre a Dádiva". In: MAUSS, Marcel. Sociologia e Antropologia. São Paulo: Cosac \& Naify, 2003.

MORALES, Juliana. Qual é a diferença entre coronavírus, covid-19 e Sars-CoV-2? Entenda. Disponível em: <https://guiadoestudante.abril.com.br/estudo/qual-e-a-diferenca-entre-coronaviruscovid-19-e-sars-cov-2-entenda/>.

PORTAL G1 https://g1.globo.com/ acessado em 31/05/2020 e 1\%06/2020.

REVISTA BRASIL DE FATO. https://www.brasildefato.com.br/2020/05/13/com-dez-mortes-porcovid-19-venezuela-estende-quarentena-por-mais-30-dias. Acessado em Maio e Junho de 2020

SALAMA, Pierre - A Pandemia como um Indicador. Site América Latina. Publicado em 07/05/2020.(https://www.americalatina.net.br/a-pandemia-como-um-indicador-por-pierre-salama), acessado em $30,31 / 05 / 2020$ 
SANTOS, Milton. A Natureza do Espaço: Técnica e Tempo, Razão e Emoção. 4. ed. 2. reimpr. - São Paulo: Editora da Universidade de São Paulo, 2006.

SARMENTO, D. F.; CASAGRANDE, C. A. Processos constitutivos das políticas educacionais no âmbito municipal: a pesquisa-ação colaborativa como postura epistemológica, metodológica e política. Práxis Educativa. Ponta Grossa, v. 9, n. 2, p. 531-552, jul./dez. 2014.

SCHÜTZEL, Fritzel Análise sociológica e linguística de narrativas Sociological and linguistic analysis of narratives. Civitas, Porto Alegre, v. 14, n. 2, p. e11-e52, maio-ago. 2014

UNA-SUS-FIOCRUZ - https://coronavirus.saude.gov.br/ acessado em 28,31/05/2020 e 1\%/06/2020.

WERNECK, Guilherme Loureiro. A pandemia de COVID-19 no Brasil: crônica de uma crise sanitária anunciada. Cadernos de Saúde Pública vol. 36 nº.5 Rio de Janeiro. Base Scielo.

https://www.scielo.br/scielo 08 de Maio de 2020. 